\title{
Accepted on Compassionate Grounds: An Admission Profile of Tamil Immigrants in Canada
}

\author{
Arul S. Aruliah
}

Since its founding as a colony, Canada has traditionally been a haven for immigrants and refugees. Successive waves of migrants have been of different national persuasions, notably French, British, Irish, Chinese, Germans, Ukrainians, Italians, and Hungarian refugees from the 1956 Revolution. Most migrants to Canada, except for the stringently controlled Chinese labour admissions, were coming from Europe until the implementation of a nonracial immigration policy by the Pearson government in 1967. This policy, coupled with the introduction of bilingual and multicultural policies of the early 1970 s, paved the way for significant migration from non-traditional source countries. Concurrent with these policies has been the opening of Canada's door for refugees from non-European sources, beginning with the admission of Ugandan Asian refugees in 1973, followed by a trickling of Latin American refugees that began with Chilean refugees, and the acceptance of Vietnamese "boat people" in the late 1970s. Most were admitted into the country under ongoing and/or special administrative procedures. But a new phenomenon emerged since the early. 1980s, whereby refugees from tyrannical regimes and ethnic conflicts would turn up at a Canadian port of entry and ask for asylum. As a result of these admissions on compassionate grounds, there emerged in the last decade a few sizable new communities in Canada, such as that of the Tamils of Sri Lanka, Iranians, Afghans, Ethiopians, Somalis, and Salvadoreans.

A significant feature of these communities is that their admissions were fuelled by inland landings, and have been almost entirely based on some

Arul S. Aruliah is the managing editor of Refuge. form of compassionate grounds, such as convention refugees, backlog clearance designated class members, their families or assisted relatives, or even independent immigrants that emerged during the administrative review of the refugee claimants back$\log$ (ADR) in 1986-87. The following is a quantitative analytical profile of the Canadian Tamil community-the largest group in this category-that has grown to 73,000 in 1994 from a meagre population of about 400 families merely a decade ago. The analysis ${ }^{1}$ is based on the landing period of migrants from Sri Lanka.

\section{Early Migration from Sri Lanka}

Sri Lankan migration to Canada began in the early 1960s with the admission, principally, of Eurasian (mixed race) population known as Burghers, who conformed to the Canadian immigrant selection criteria at that time. The English-educated population began their move from Sri Lanka (or Ceylon as it was known before 1972) to the U.K., Australia, and Canada following the introduction of Sinhala as the only official language in 1956. Some 500 Ceylonese had been admitted by the time Canada moved to nonracial selection of immigrants in 1967. Thereafter, the Sinhalese, Tamil, and other communities began to immigrate to Canada; they were mostly professionals arriving via England after completing their studies in that country. By 1973 , there was a total of 1,747 landings. When the major communal upheaval broke out in Sri Lanka in July $1983,{ }^{2}$ a total of 4,373 Sri Lankans-of which an estimated 30 percent were Tamils-had been admitted to Canada.

\section{Admission To Canada From 1983}

Admissions of Sri Lankan citizens to Canada between 1964-93 are shown on a logarithmic scale in Figure 1. Of the total population of 51,631 persons admitted by 1993 (see Table 1), about 95 percent of the landings took place in the last ten years in four identifiable stages, which correspond to the introduction of the special program for Sri Lanka in 1983, the ADR program in 1986 , the refugee backlog clearance designated class program in 1988, and the determination of convention

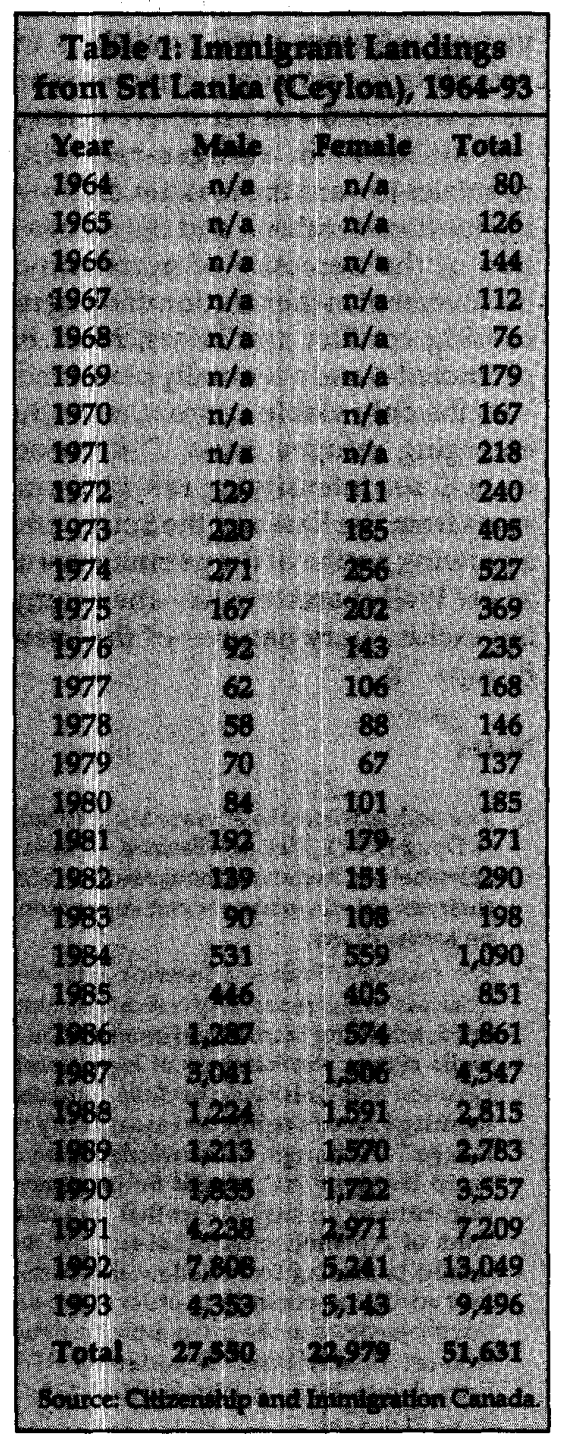


refugee status under Bill C- 55 by the newly instituted Immigration and Refugee Board (IRB) from 1989.

Introduction of the special program for Sri Lanka. Following the communal riots that began in Colombo in July 1983, Immigration Minister John Roberts, on the recommendation of his senior advisors, introduced special relief measures for the affected people of Sri Lanka. The program came in response to the representations made by an active and closely-knit group of the Toronto Sri Lankan Tamil community, with the assistance of church groups in Toronto, and organized by the Tamil Eelam Society of Canada.

This program, introduced in September 1983, allowed the Sri Lankan refugee claimants, students, and visitors who were in Canada at the time, to apply for landing from inside Canada; imposed a moratorium on removals to Sri Lanka; allowed eligible residents to sponsor affected relatives under relaxed selection criteria; and authorized the issue of Minister's permits for those persons whose lives were deemed to be in danger. The program became the most effective source of protection for the affected population. Concurrently, however, the Government imposed visa requirements on Sri Lankan nationals.

The refugee claimants who arrived after the program date were assessed according to the normal determination method by the Refugee Status Advisory Committee (RSAC). However, the Singh decision ${ }^{3}$ by the Supreme Court, on April 4, 1985, contributed significantly to the refugee backlog. Community activists, supported by church and academic leaders, lobbied for the inclusion of Sri Lanka in the B1 list of countries, which would enable immigration officers to issue a minister's permit, instead of routing the claimants through the RSAC paper review process. The so-called B1 list consisted of countries of the former Soviet Bloc, and some Latin American and Southeast Asian countries. At a meeting held in Toronto in April 1986 with the Minister of State (Immigration) Walter McLean, community activists expressed the view that Tamil claimants were being "miscategorized." 4 Commenting on the effect of reasoned lobbying, Professor Howard Adelman notes that "the incentive to fulfill these moral obligations [of not returning
Figure 1: Thirty Years of Sri Lankan Immigration to Canada, 1964-93

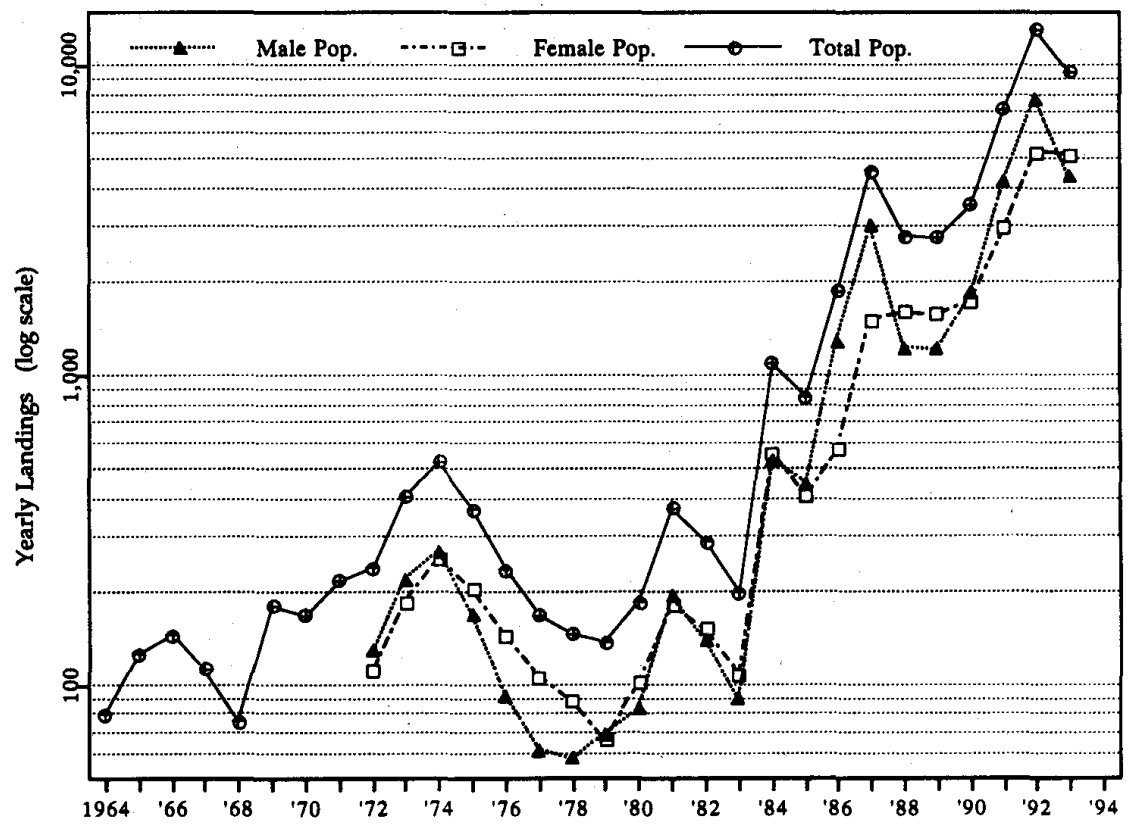

claimants to country of alleged persecution] is helped by the fact that ... the Tamil community ... provide[s] a small but forceful lobby on [their] behalf...." (Adelman et al, 1994). In May 1986, the Minister announced an administrative program for refugee claims clearance pursuant to the Supreme Court ruling and, at the same time, the B1 countries list was updated to include Sri Lanka.

Landings under the $A D R$ program. The second wave of landings took place under this program in 1986-87. This program effectively sidestepped the refugee claims, and assessed the applicants for economic adaptability. Except for a very few cases in which claimants were dependent on social assistance, about 4,500 applicants-almost all the Sri Lankan claimants in the program-were landed and their families began to be reunited in the following years.

Although thousands of Tamil refugees had sought asylum in preceding years, the arrival of 155 Tamil men, women, and children off the coast of Newfoundland in August 1986 captured the imagination of both the Canadian and international media. The new Minister of State (Immigration) Gerry Weiner and his senior Minister Benoit Bouchard had assumed their portfolios only a few weeks earlier. Apparently overwhelmed by the initial euphoria, the Minister announced that these asylum-seekers would be accepted, even though he was simply implementing the procedure that had been in place since May 1986. By then, of course, the merits of maintaining the B1 list of countries were misunderstood by the public. Given the policy of the government to assist refugees in distress, this process was probably the most effective and least expensive administrative tool for recognizing discontinuous displacement in a given country.

The B1 list, and the policy of nonremoval to these countries, was discontinued in February 1987, and the refugee claims reverted to the virtually non-functioning RSAC process. An estimated 2,500 permits were issued 


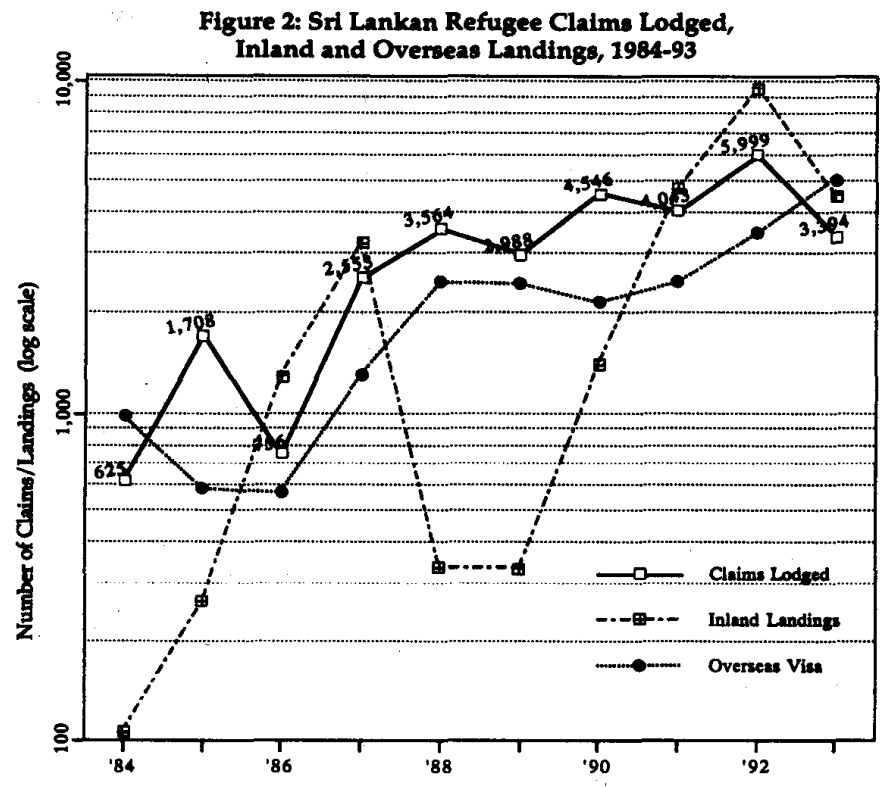

for Sri Lankan claimants while that country was on the B1 list and, along with this group, the Newfoundland arrivals also became part of the ADR backlog. In the intervening period, the new refugee determination legislation, Bill C-55, was being formulated in Parliament, and was enacted on January 1 , 1989. The refugee claimants who were in the system until this date became members of the new Refugee Backlog Clearance Designated Class.

Landings under the Designated Class program. Under this program, a total of 7,385 persons were landed from 1989 to 1993 , representing about 85 percent of eligible persons. An increase in the landings of women, as shown in Figure 4-due to family reunificationsis evident immediately following the program landing periods. Concurrently, a reverse trend is apparent with the workers' share, effected by the impact of the increased dependents' share.

Landings under C-55. A total of 20,970 Sri Lankan refugee claims were lodged with IRB between 1989-93, with an average acceptance rate of 90 percent. Of which, a total of 10,401 Convention refugees were landed during the same period. It is pertinent to note that only one Sri Lankan claimant was landed as a Convention refugee in 1983.
H a vi n $\mathrm{g}$ looked at factors that propelled the exponential growth of Sri Lankan $\mathrm{mi}$ gration to Canada, let us turn to the profile of the community based on some of the immigrant selection criteria. For this purpose, a small sample of pre-1983 immigrant population is used as the reference group. The following parameters, viz. landings, gender and age, marital status, immigrant class, native language, educational qualifications, and worker/dependent ratios, are measured and their percentage share for each year from 1980 to 1993 is shown in Figures 3 and 4. Unless stated otherwise, all statistical data refer to the period 1980-93.

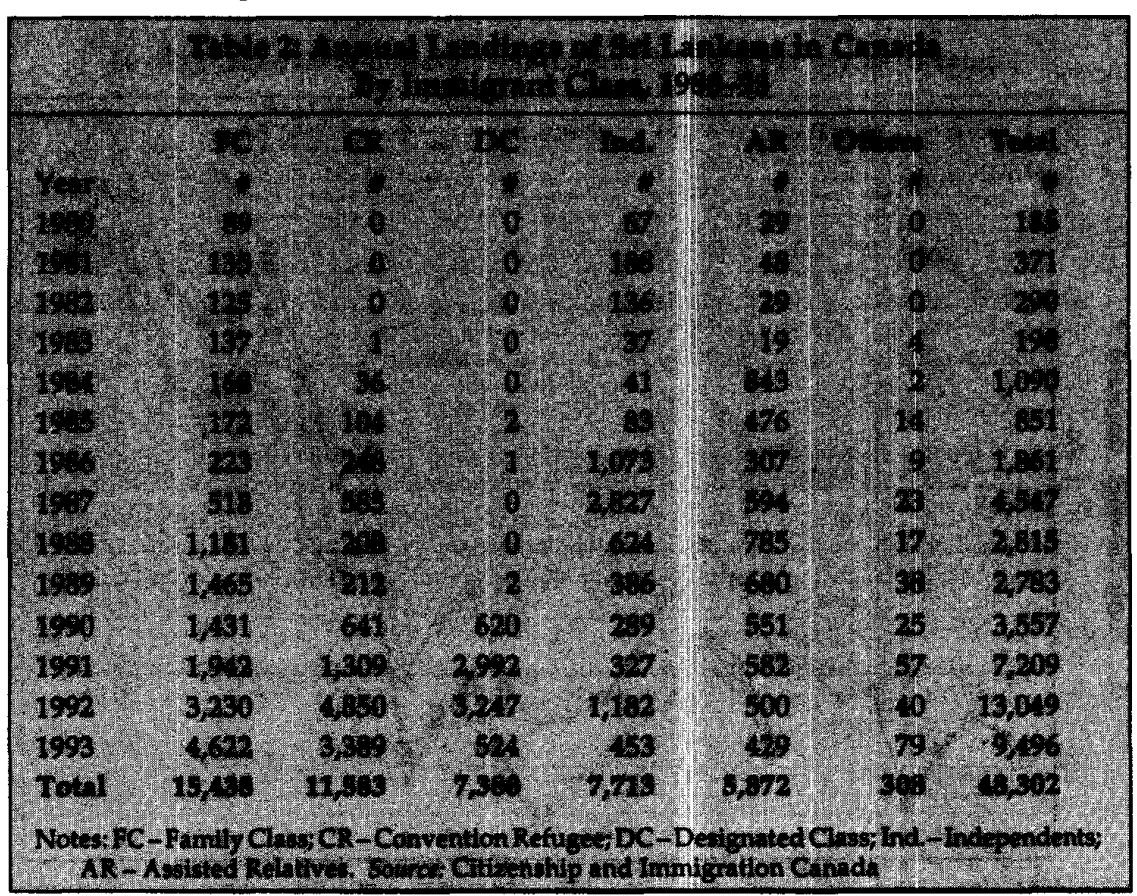




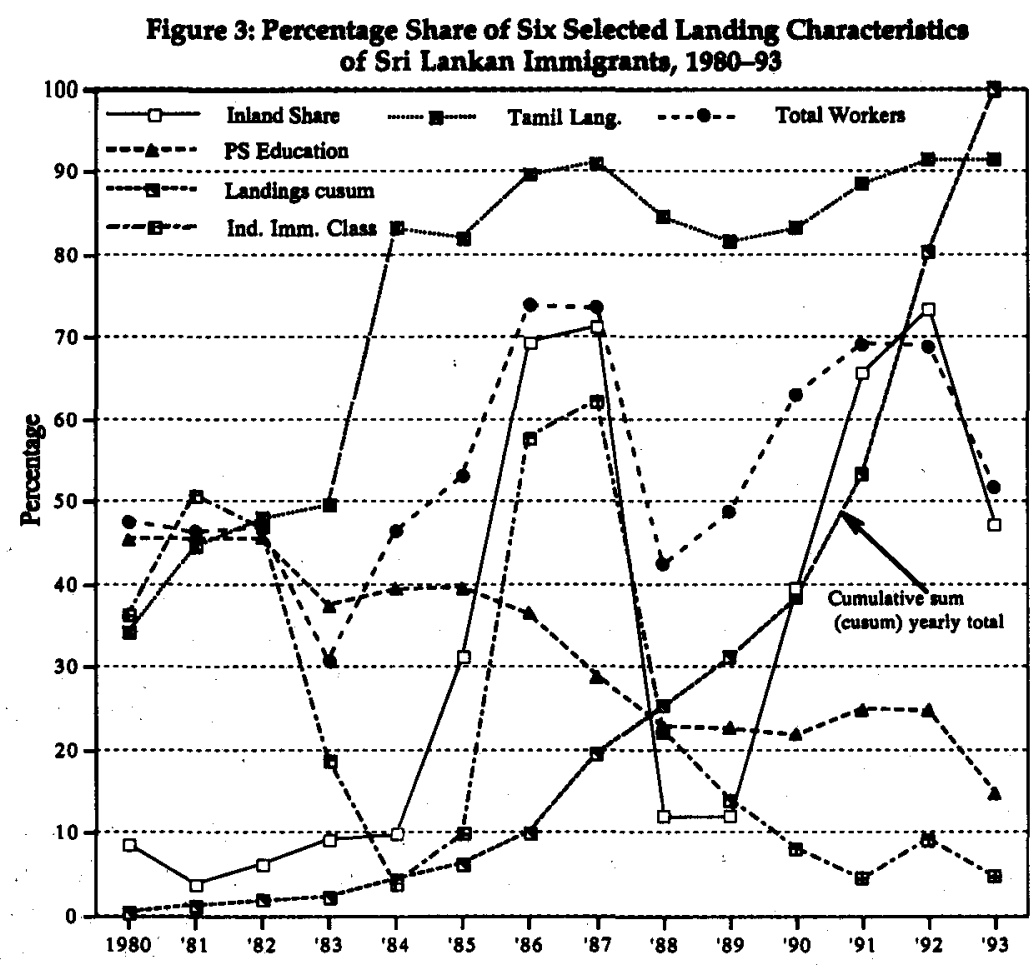

(CICs), 21,974 persons (85 percent) were landed by Metro Toronto and Mississauga CICs, Montréal CICs landed 2,558 persons, and 1,310 persons were landed in $69 \mathrm{CICs}$ across the country.

Of the 22,460 persons processed overseas, 70 percent were processed at the Colombo visa office, 12 percent in New Delhi, 5 percent in London, England, and the rest at 72 visa offices around the world.

\section{Gender, Age, and Marital Status}

Figure 4 illustrates the percentage share of male and female populations, and that of the population under the age of 45 years. From 1980 to 1993, 26,481 males and 21,821 females were landed. As much as 88.4 percent of the male population and 81.7 percent of the females were under 45 years of age at the time of admission to Canada. Overall, male residents constitute about 55 percent of the total population, and the pronounced effects of gender differences can be observed during $A D R$ and Designated Class landings, as the majority of claimants were young males. At the time of landing, there were 17,277 males and 12,419 females aged 20-44 years. Of the total population, 26,369 persons were single; 19,798 were married; 1,788 were widowed; and 347 persons were separated from their spouse at the time of landing. The single marital status share shown in Figure 4 is reflective of the percentage share of men aged 20 44 years.

\section{Immigrant Class}

Table 2 summarizes the landings of Sri Lankan citizens by immigrant class from 1980 to 1993 . The yearly percentage share of independent immigrants is shown in Figure 3, and the immigrant class share in Figure 5. It is instructive to note that immigrant class assignment simply denotes the emphasis placed on a given person at the time of his or her landing, and is not necessarily an indicator of whether that person would pass the test of another category.

Inadvertently, an interesting "test" took place during ADR landings in 1986-87. The refugee claimant population was evaluated and processed for landing based on their ability to support themselves and their dependents.
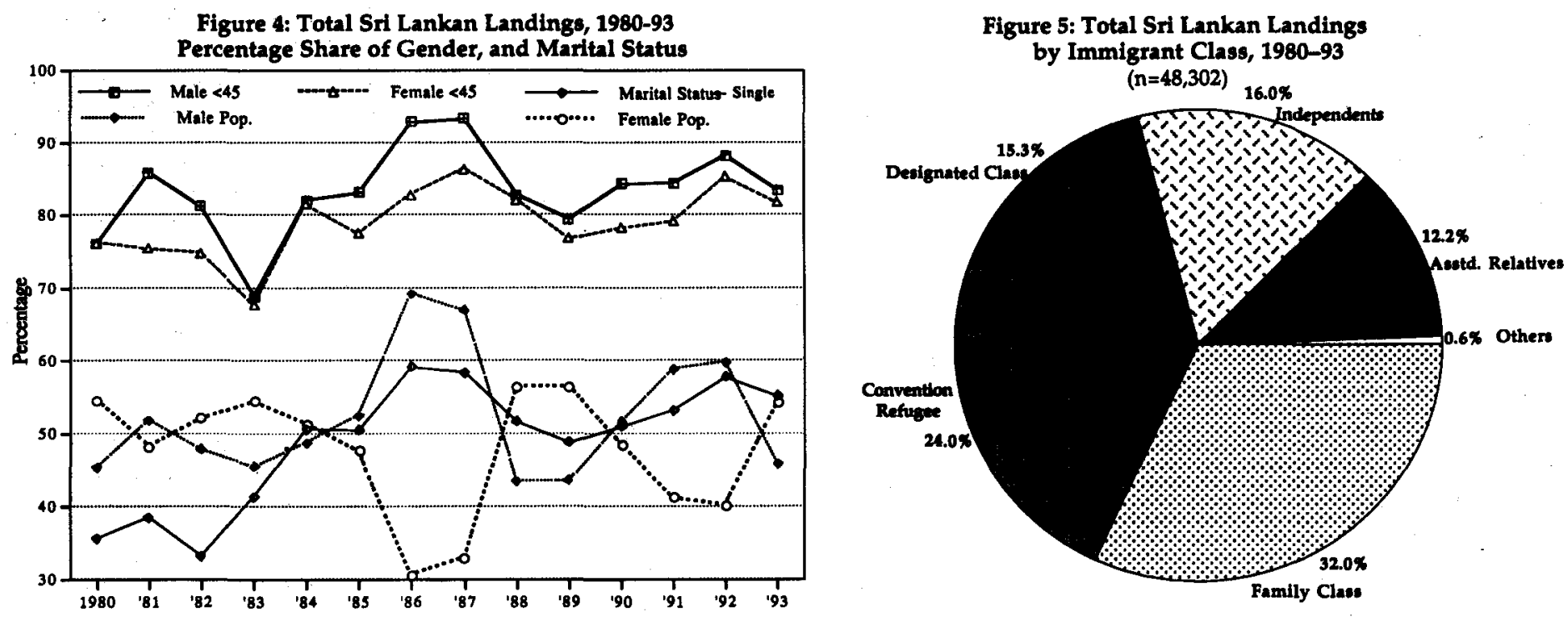

Refuge, Vol. 14, No. 4 (Aug.-Sept. 1994)) 
As can be seen in Figure 3, nearly 60 percent of the landings were classified as independents during this processing. In other periods, however, most of the inland claimants were not evaluated on a similar basis, and correspondingly, independents' share showed a downward trend in relation to the other categories of immigrant class. Entrepreneurs, retired persons, self-employed, investors, and live-in caregivers formed less than one percent of the total landings. There were no landings of claimants under Bill-86 Post-Determination Refugee Claimants in Canada Class (PDRCC).

\section{Educational Level}

The percentage share of persons with at least some post-secondary (PS) education is shown in Figure 3. About 45 percent of the reference (1980-82) population had some post-secondary level education, i.e., about one in two Sri Lankans landed had tertiary level education. As the years progressed, however, this share showed a downward trend, which is to be expected in a young population fleeing zones of prolonged conflict.

\section{Occupation}

Percentage share of workers in the landed Sri Lankan population is shown in Figure 3.

The progressive trend, driven by the predominance of the single population until 1985, was interrupted by the arrival of family members in 198889, a follow-up result of ADR landings. A similar trend is evident in the post-backlog family reunions in 1991-92.

Of the total population of 48,302 , there were 9,818 workers and 18,484 non-worker dependents at the time of landing, with 1:1.6 worker/dependent ratio. Non-workers included spouses, children, students, and retired persons.

\section{Native Language}

Sample computing of pre-1983 landings (1980-82) indicates that 43.3 percent declared Tamil as their mother tongue, with corresponding percentages of 38.5 for Sinhala, and 12.8 for English. However, as shown in Figure 3 , the post-1983 landings in Canada have been predominantly Tamilspeaking. Tamil constituted nearly 88 percent of the total landings between 1980 and 1993; Sinhala is spoken by 7.6 percent of the population, and 3 percent of the immigrants declared English as their mother tongue.

One-and-a-half percent of the Sri Lankan citizens landed in the same period shared more than 40 languages; among them 103 persons spoke Swahili, 64 Punjabi, 16 one of the African languages, 14 Cantonese, eight French, and one each of Amharic, Japanese, Ibo and Yoruba - these probably being attributable to children raised in those environments. The population has not been analyzed for its fluency in English or French. However, English was the official language of administration in Sri Lanka before 1956.

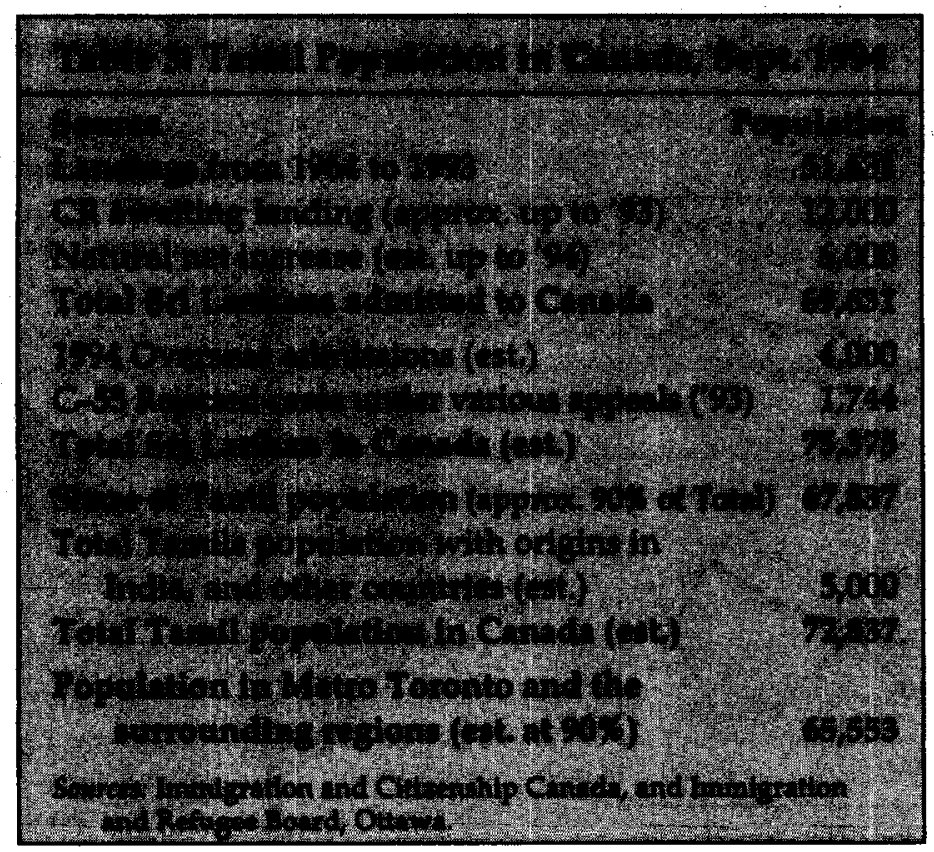

\section{The Community}

The Canadian Tamil community in 1994, as summarized in Table 3 , is about 73,000. Based on the landing centres' data, it is further estimated that about 90 percent of this population is in the greater Toronto area.

The above analysis of the landed Sri Lankan population indicates that an overwhelming majority of these persons were admitted under some form of compassionate considerations. The community is mostly composed of young adult Tamils, and has a relatively high worker/dependents ratio. About one-half of the population is single, and one in four had some post-secondary education at the time of landing.

Based on these criteria, compassionate considerations notwithstanding, the characteristics of this population correspond with the primary goal of the Canadian immigrant selection process of admitting a young and industrious population capable of becoming an asset to this country.

\section{Notes}

1. The author would like to thank Yumiko Iida, graduate student of Political Science at YorkUniversity, and Anusha Aruliah, a student of Political Science and Philosophy at the University of Toronto, for their research assistance in the collection of data.

2. See the special issue of Refuge, Vol.13, No.3, June 1993, for an account of the emergence of ethnic conflict in Sri Lanka and factors leading to the July 1983 riot, in which hundreds of Tamils were murdered and a large number were made refugees.

3. In Singh v. Canada (Minister of Employment and Immigration) the Supreme Court of Canada ruled that the Canadian Charter of Rights and Freedoms applies to everyone in Canada. Hence an oral hearing was mandated for refugee hearing appeals.

4. Communication from the Minister of State (Immigration).

\section{References}

Adelman, Howard. 1994. "Justice, Immigration and Refugees." In Immigration and Refugee Policy, Australia and Canada Compared, edited by. Adelman, H., Allan Borowski, Meyer Burstein and Lois Foster, Vol. 1, 87. Toronto: University of Toronto Press (and Melbourne University Press, Australia). $\square$ 